\title{
Relationship between Total Serum Cholesterol Level and Nutritional and Physical Status in Nepalese Rural People
}

\author{
Kazue ItoH, ${ }^{1, *}$ Terukazu Kawasaki, ${ }^{2}$ Tetsuro OGaKi, ${ }^{2}$ Keiko Uezono, ${ }^{2}$ \\ Yutaka Yoshimizu, ${ }^{3}$ Tetsuro OsaKa, ${ }^{4}$ Chikako WaKana, ${ }^{1}$ \\ Junko NaKayama, ${ }^{5}$ Masaharu OHnaka, ${ }^{6}$ Gopal P. ACHARYa, ${ }^{7}$ \\ and Michihiko OGATA ${ }^{2}$ \\ ${ }^{1}$ Division of Food and Nutrition, Nakamura Gakuen College, \\ Jonan-ku, Fukuoka 814, Japan \\ ${ }^{2}$ Institute of Health Science, Kyushu University, Kasuga 816, Japan \\ ${ }^{3}$ Department of Health and Physical Education, Kurume University, \\ Kurume 830, Japan \\ ${ }^{4}$ Fukuoka Junior College of Technology, Fukuoka 813, Japan \\ ${ }^{5}$ Hamamatsu Medical College, Hamamatsu 431-31, Japan \\ ${ }^{6}$ Department of Nutrition, School of Medicine. The University of Tokushima, \\ Tokushima 770, Japan \\ ${ }^{7}$ Institute of Medicine, Tribhuvan University, Kathmandu, Nepal
}

(Received May 6, 1992)

\begin{abstract}
Summary To investigate the nutritional condition in a hilly village (Kotyang) and a suburban village (Bhadrakali) in Nepal and to clarify the possible cause of the difference in total serum cholesterol level between the two groups of villagers habitually eating low fat diets, we carried out a nutrition survey using the 24 -h recall method and blood sampling in 403 subjects (204 men and 199 women) in the hilly village and 466 (244 men and 222 women) in the suburban village. Total serum cholesterol was statistically significantly lower in the hilly villagers than in the suburban villagers for both sexes, but HDL-cholesterol was not. In both villages, $82 \%$ of the total energy was taken from carbohydrate, $7-8 \%$ from fat and $10 \%$ from protein. Energy, protein, fiber, potassium, magnesium, monounsaturated fatty acid, polyunsaturated fatty acid, and vitamin A in the hilly villagers were significantly higher than those in the suburban villagers. Total serum cholesterol was significantly associated with age and body fat percentage, suggesting that total serum cholesterol level was not directly associated with total fat intake in these Nepalese people.

Key Words total serum cholesterol, HDL-cholesterol, apoprotein, fat intake, cereal energy intake, fiber intake, potassium intake, magnesium intake, body fat percentage, maximal oxygen uptake, Nepal
\end{abstract}

* To whom requests for reprints should be addressed. 
The relatively high intake of saturated fatty acid and cholesterol are considered to be significant factors in raising serum cholesterol and in the high prevalence of coronary heart disease $(1-6)$. However, most of the studies were done in the western population and there is limited information from the other populations having different dietary patterns and life-styles.

In the Japan-Nepal Health Scientific Expedition in 1987, we found that the Nepalese people consume higher carbohydrate and lower fat diets than the western populations, and even among the Nepalese people, the inhabitants living in a hilly village revealed extremely low serum cholesterol levels as compared with those in a suburban village (7). In order to clarify the possible cause of this difference, we compared the characteristics of diet composition, physical activity, and serum lipids between the subjects in the two villages.

\section{SUBJECTS AND METHODS}

Subjects. Two typical rural areas in Nepal which have distinctive features were selected as survey sites in this study. The subjects were studied for about 1 month from August through September, 1987. One rural area was a hilly village (Kotyang) located about $30 \mathrm{~km}$ east of Kathmandu, and the other was a suburban village (Bhadrakali), adjacent to north of Kathmandu. The two villages are about $1,200 \mathrm{~km}$ above sea level and $75 \mathrm{~km}$ apart from each other (7).

A total of 403 subjects (204 men and 199 women) in Kotyang and 466 (244 men and 222 women) in Bhadrakali, between 20 to 84 years old, participated in the nutrition survey. The number of households surveyed was 122 out of 183 in the former and 297 out of 388 in the latter. Ninety-eight percent of the villagers in Kotyang and $83 \%$ in Bhadrakali were farmers, and $9 \%$ of the latter were wage earners.

The study protocol including a blood sampling was explained by the Nepalese doctors to all subjects, and was performed only after informed consent was obtained from the subjects themselves.

Nutritional survey. The survey to determine nutrient intake was carried out by the 24-h recall method, in which the 24-h consumption of energy, protein, fat, calcium $(\mathrm{Ca})$, magnesium $(\mathrm{Mg})$, potassium $(\mathrm{K})$, and sodium $(\mathrm{Na})$ was calculated from the 24-h food record obtained by interviewing each participant using food model. More than 30 kinds of food materials were collected from the usual dietary menu of 23 randomly selected houses in both areas. They were dried to constant weight at $90^{\circ} \mathrm{C}$ in Nepal and were transported to Japan for the analysis of their nutrient contents. The energy contents were determined by the Bombe-Calory methods, protein by the Kjeldahl method and fat by the heat-ether method, respectively. $\mathrm{Na}$ and $\mathrm{K}$ were measured by the flame photometry method and $\mathrm{Ca}$ and $\mathrm{Mg}$ by the flame atomic absorption method. All of these analyses were performed in Japan.

Blood chemistries. Approximately $10 \mathrm{ml}$ of blood was drawn from subjects in 
supine position; they had agreed to blood sampling, after overnight fasting. The blood specimen was centrifuged and the serum was kept frozen at $-80^{\circ} \mathrm{C}$ until the chemical analysis. Frozen serum was transported to Japan in dry ice. Total protein, total cholesterol, high density lipoprotein (HDL)-cholesterol and triglycerides in serum, and $\mathrm{Ca}$ and $\mathrm{Mg}$ in serum were measured by standard techniques using autoanalyzers (Olympus AU-5000 and AUA-8000: Olympus Optical Co., Ltd., Tokyo, Japan; or ACP-5040: Eppendorf Co., Ltd., Germany) at CRC Laboratories in Fukuoka.

Anthropometry and physical activity. Body height and body weight were measured. Body mass index (BMI) was calculated by the equation of $\mathrm{kg} / \mathrm{m}^{2}$ and the body fat percentage $(\%$ Fat $)$ by the equation of Nagamine and Suzuki ( 8$)$, using skinfold thickness values which were measured at the triceps and subscapular sites by one examiner (T.O.) using a skinfold caliper. Maximal oxygen uptake $\left(\dot{V}_{\mathrm{O}_{2} \max }\right)$ was measured in 301 subjects ( 99 men and 35 women in Kotyang; 136 men and 31 women in Bhadrakali), respectively, by Margaria's indirect method (9).

Statistical analysis. Statistical methods to assess the relationship of the variables to total serum cholesterol included the computation of the simple and the partial correlation coefficients. The correlation coefficient between total serum cholesterol and $\dot{V}_{\mathrm{O}_{2} \max }$ was computed by the partial correlation analysis adjusted for age and $\%$ Fat because the determined value for $\dot{V}_{\mathrm{O}_{2} \max }$ was small. Statistical results were expressed as mean \pm standard deviation (SD). For the comparison between the two groups the Student's $t$-test and the non-parametric test were employed. A $p$-value of less than 0.05 was considered to be significant.

\section{RESULTS}

\section{Subjects' profile}

The subjects' profile is shown in Table 1. We examined 67.5\% (62.2\%) and $51.4 \%(45.9 \%)$ of adult men (women) in Kotyang and Bhadrakali, respectively. Age and sex distributions of the subjects studied were not statistically significantly different from those of the entire population in the two villages, although the women studied in Bhadrakali were younger than those in Kotyang. The body height and weight were not remarkably different, while \% Fat was significantly greater in Bhadrakali than in Kotyang in both sexes.

\section{Total serum cholesterol and HDL-cholesterol}

Total serum cholesterol concentration was statistically significantly lower in Kotyang than in Bhadrakali, whereas HDL-cholesterol was not, as shown in Table 2. Serum total protein and serum albumin concentration were significantly lower in Kotyang than in Bhadrakali. The subjects in Kotyang showed higher serum $\mathrm{Mg}$ and lower serum $\mathrm{Ca}$ than those in Bhadrakali. The distribution of total serum cholesterol for subjects is shown in Fig. 1.

Although serum apoprotein (apo) AI, AII, and B were significantly lower in 
Table 1. Subjects' profile by sex and village.

\begin{tabular}{lccccc}
\hline & \multicolumn{2}{c}{ Men } & & \multicolumn{2}{c}{ Women } \\
\cline { 2 - 3 } \cline { 5 - 6 } & Kotyang & Bhadrakali & & Kotyang & Bhadrakali \\
\hline No. of subjects & 204 & 244 & & 199 & 222 \\
Age (years) & $40 \pm 14$ & $38 \pm 15$ & & $41 \pm 14$ & $37 \pm 14^{* *}$ \\
Height $(\mathrm{cm})$ & $159 \pm 6.5$ & $161 \pm 7$ & & $148 \pm 5$ & $149 \pm 6$ \\
Weight $(\mathrm{kg})$ & $47.1 \pm 5.9$ & $47.7 \pm 7.2$ & & $41.2 \pm 5.1$ & $41.3 \pm 5.9$ \\
BMI $\left(\mathrm{kg} / \mathrm{m}^{2}\right)$ & $18.6 \pm 1.7$ & $18.5 \pm 2.1$ & & $18.9 \pm 2.0$ & $18.8 \pm 2.1$ \\
$\%$ Fat $(\%)$ & $10.8 \pm 1.8$ & $15.0 \pm 4.0^{* * * *}$ & & $14.4 \pm 8.4$ & $20.7 \pm 5.1^{* * *}$ \\
SBP $(\mathrm{mmHg})$ & $107 \pm 12$ & $118 \pm 14^{* * *}$ & & $109 \pm 14$ & $110 \pm 14$ \\
DBP $(\mathrm{mmHg})$ & $66 \pm 11$ & $78 \pm 12^{* * *}$ & & $67 \pm 11$ & $72 \pm 12^{* * *}$ \\
\hline
\end{tabular}

$\mathrm{M} \pm \mathrm{SD}$. BMI, body mass index; $\%$ Fat, body fat percentage; SBP, systolic blood pressure; DBP, diastolic blood pressure. ${ }^{* *} p<0.01$, ${ }^{* * *} p<0.001$ (vs. Kotyang).

Table 2. Mean and standard deviation of serum parameters of subjects by sex and village.

\begin{tabular}{lccccc}
\hline \multirow{2}{*}{\multicolumn{1}{c}{ Parameters }} & \multicolumn{2}{c}{ Men } & & \multicolumn{2}{c}{ Women } \\
\cline { 2 - 3 } \cline { 5 - 6 } \cline { 5 - 6 } & Kotyang & Bhadrakali & & Kotyang & Bhadrakali \\
\hline Hemoglobin $(\mathrm{g} / \mathrm{dl})$ & $14.5 \pm 2.1$ & $14.9 \pm 1.5$ & & $12.5 \pm 2.4$ & $13.1 \pm 1.6^{* *}$ \\
Total protein $(\mathrm{g} / \mathrm{dl})$ & $7.1 \pm 0.5$ & $7.7 \pm 0.5^{* * *}$ & & $7.1 \pm 0.6$ & $7.6 \pm 0.6^{* * *}$ \\
Serum albumin $(\mathrm{g} / \mathrm{dl})$ & $4.1 \pm 0.3$ & $4.3 \pm 0.2^{* * *}$ & & $4.0 \pm 0.3$ & $4.2 \pm 0.2^{* * *}$ \\
Total cholesterol $(\mathrm{mg} / \mathrm{dl})$ & $133 \pm 26.4$ & $145 \pm 29.1^{* * *}$ & & $140 \pm 28.2$ & $147 \pm 27.6^{*}$ \\
HDL-cholesterol $(\mathrm{mg} / \mathrm{dl})$ & $36.7 \pm 7.5$ & $37.8 \pm 10.1$ & & $39.0 \pm 8.1$ & $40.8 \pm 9.3$ \\
Triglyceride $(\mathrm{mg} / \mathrm{dl})$ & $88 \pm 39.7$ & $115 \pm 68.0^{* * *}$ & & $90 \pm 48.7$ & $112 \pm 68.8^{* * *}$ \\
Serum calcium $(\mathrm{mEq} /$ liter $)$ & $4.60 \pm 0.28$ & $4.75 \pm 0.23^{* * *}$ & & $4.50 \pm 0.25$ & $4.62 \pm 0.24^{* * *}$ \\
Serum magnesium $(\mathrm{mEq} /$ liter $)$ & $1.94 \pm 0.16$ & $1.87 \pm 0.16^{* * *}$ & & $1.91 \pm 0.16$ & $1.81 \pm 0.15^{* * *}$ \\
\hline
\end{tabular}

$\mathrm{M} \pm \mathrm{SD} . *_{p}<0.05,{ }^{* *} p<0.01,{ }^{* * *} p<0.001$ (vs. Kotyang).

Kotyang than in Bhadrakali, as shown in Table 3, apoB/apoAI was the same in the two villages for both sexes.

\section{Dietary intakes}

The intakes of different kinds of foods are shown in Table 4. The usual daily diet of both villagers mainly consisted of bhaat, dido, and tarukali. Achar and dal were also seen in their diet. The staple foodstuffs in Kotyang and Bhadrakali were corn and wheat, respectively. In Kotyang, the average consumption of green leafy vegetables and alcohol was greater, and that of rice, wheat, sugar, beans, and beverage was smaller than in Bhadrakali. Alcohol intake for both sexes was significantly greater in Kotyang than in Bhadrakali $(16.4 \pm 27.6$ vs. $3.8 \pm 14.5 \mathrm{~g}$ /day for men and $12.2 \pm 20.8$ vs. $0.9 \pm 4.5 \mathrm{~g}$ /day for women) and the percentage of drinkers was also significantly higher in Kotyang than in Bhadrakali (60 vs. $43 \%$ 


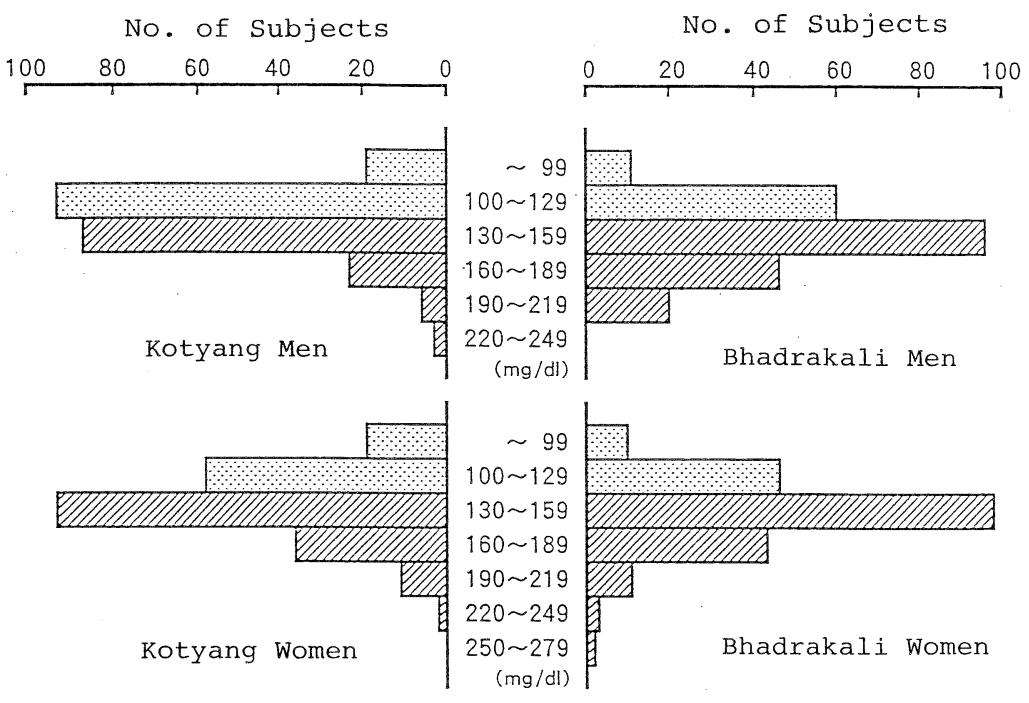

Fig. 1. Distribution of total cholesterol for subjects by sex and village.

Table 3. Apo-protein of subjects by sex and village.

\begin{tabular}{lccccc}
\hline & \multicolumn{2}{c}{ Men } & & \multicolumn{2}{c}{ Women } \\
\cline { 2 - 3 } \cline { 5 - 6 } & Kotyang & Bhadrakali & & Kotyang & Bhadrakali \\
\hline No. of subjects & 49 & 48 & & 44 & 51 \\
Apo AI $(\mathrm{mg} / \mathrm{dl})$ & $89 \pm 21.0$ & $103 \pm 21.2^{*}$ & & $110 \pm 21.2$ & $113 \pm 18.8$ \\
Apo AII $(\mathrm{mg} / \mathrm{dl})$ & $21.1 \pm 6.4$ & $28.4 \pm 11.4^{* *}$ & & $25.0 \pm 5.0$ & $27.8 \pm 5.8^{*}$ \\
Apo B $(\mathrm{mg} / \mathrm{dl})$ & $69.1 \pm 18.8$ & $80.3 \pm 19.7^{*}$ & & $77.8 \pm 16.8$ & $86.3 \pm 15.8^{*}$ \\
Apo CII $(\mathrm{mg} / \mathrm{dl})$ & $2.9 \pm 1.8$ & $2.1 \pm 1.1$ & & $1.7 \pm 1.0$ & $2.4 \pm 1.1^{* *}$ \\
Apo CIII $(\mathrm{mg} / \mathrm{dl})$ & $4.4 \pm 1.7$ & $5.1 \pm 2.2$ & & $5.4 \pm 2.8$ & $6.0 \pm 2.2$ \\
\hline
\end{tabular}

$\mathrm{M} \pm \mathrm{SD} .{ }^{*} p<0.05,{ }^{* *} p<0.01$ (vs. Kotyang).

for men and 54 vs. $25 \%$ for women). Drinking tea with sugar was common in Bhadrakali, whereas there was no habit of drinking tea in Kotyang. Animal products (such as meat, fish, and eggs) were not usually taken except for a small amount of water buffalo, and only during the festival season. Both villagers took many spices, in particular red pepper in tarukali and achar.

\section{Nutrient intakes}

The daily ingestion of the various nutrients are summarized in Table 5. In both villages, $82-83 \%$ of total energy was taken from carbohydrates, $7-8 \%$ from fat and $10 \%$ from protein. It should also be noted that the cereal energy ratio was remarkably high $(85 \%)$ in both villages.

The intake of energy and protein per $\mathrm{kg}$ of body weight, fiber, $\mathrm{K}, \mathrm{Mg}$, and 
Table 4. Daily intakes of food group by sex and village.

\begin{tabular}{|c|c|c|c|c|}
\hline \multirow{2}{*}{ Food group } & \multicolumn{2}{|c|}{ Men (g/day) } & \multicolumn{2}{|c|}{ Women (g/day) } \\
\hline & Kotyang & Bhadrakali & Kotyang & Bhadrakali \\
\hline Rice & $284 \pm 217$ & $317 \pm 133^{*}$ & $236 \pm 163$ & $277 \pm 139 *$ \\
\hline Wheat flower & $80 \pm 111$ & $127 \pm 183^{* *}$ & $95 \pm 124$ & $145 \pm 179 * *$ \\
\hline Corn & $610 \pm 568$ & $83 \pm 215^{* * *}$ & $402 \pm 503$ & $101 \pm 221^{* * *}$ \\
\hline Potato & $49 \pm 110$ & $135 \pm 160^{* * *}$ & $65 \pm 123$ & $131 \pm 156^{* * *}$ \\
\hline Sugar & $0.7 \pm 4.6$ & $25.5 \pm 26.2^{* * *}$ & $0.2 \pm 1.1$ & $16.3 \pm 16.7^{* * *}$ \\
\hline Oil and fat & $0.1 \pm 1.0$ & $0.4 \pm 3.7$ & $0.1 \pm 0.4$ & $0.4 \pm 3.3$ \\
\hline Green vegetable & $60 \pm 57$ & $12 \pm 28 * * *$ & $51 \pm 45$ & $13 \pm 24 * * *$ \\
\hline Other vegetable & $25 \pm 39$ & $24 \pm 30$ & $24 \pm 36$ & $24 \pm 28$ \\
\hline Meat & $8 \pm 34$ & $18 \pm 47^{*}$ & $5 \pm 25$ & $10 \pm 37$ \\
\hline Fish & $0 \pm 0$ & $0 \pm 0$ & $0 \pm 0$ & $0 \pm 0$ \\
\hline Egg & $2 \pm 15$ & $3 \pm 15$ & $0 \pm 0$ & $0.8 \pm 6.2$ \\
\hline Milk & $32 \pm 87$ & $47 \pm 91$ & $35 \pm 86$ & $36 \pm 77$ \\
\hline Chan $^{\mathrm{a}}$ & $665 \pm 975$ & $107 \pm 453^{* * *}$ & $447 \pm 713$ & $28 \pm 140 * * *$ \\
\hline Beverage & $31 \pm 96$ & $225 \pm 209^{* * *}$ & $14 \pm 46$ & $137 \pm 125^{* * *}$ \\
\hline
\end{tabular}

$\mathrm{M} \pm$ SD. ${ }^{a}$ Local alcoholic drink. ${ }^{*} p<0.05,{ }^{* *} p<0.01,{ }^{* * *} p<0.001$ (vs. Kotyang).

Table 5. Daily nutrient intakes and nutritional ratios by sex and village.

\begin{tabular}{lccccc}
\hline & \multicolumn{2}{c}{ Men } & & \multicolumn{2}{c}{ Women } \\
\cline { 2 - 3 } \cline { 5 - 6 } & Kotyang & Bhadrakali & & Kotyang & Bhadrakali \\
\hline Energy (kcal) & $2,374 \pm 905$ & $1,959 \pm 749^{* * *}$ & & $2,078 \pm 893$ & $1,781 \pm 680^{* * *}$ \\
Energy supplies from & & & & & \\
$\quad$ Protein (\%) & $10.1 \pm 1.5$ & $9.3 \pm 1.5^{* * *}$ & & $10.0 \pm 1.6$ & $9.6 \pm 1.5^{* *}$ \\
Fat (\%) & $7.4 \pm 3.0$ & $8.3 \pm 4.0^{* *}$ & & $7.1 \pm 3.0$ & $7.9 \pm 3.9^{*}$ \\
Carbohydrate (\%) & $82.5 \pm 4.0$ & $82.4 \pm 4.9$ & & $82.9 \pm 4.1$ & $82.5 \pm 4.7$ \\
Protein (g) & $59.4 \pm 25.2$ & $46.0 \pm 21.2^{* * *}$ & & $52.0 \pm 25.6$ & $43.1 \pm 19.2^{* * *}$ \\
$\quad$ Animal protein (g) & $3.1 \pm 4.7$ & $2.4 \pm 3.8$ & & $1.8 \pm 3.2$ & $1.7 \pm 3.6$ \\
Animal protein ratio (\%) & $5.5 \pm 8.9$ & $5.7 \pm 9.2$ & & $4.1 \pm 8.1$ & $4.2 \pm 8.6$ \\
Fat (g) & $19.3 \pm 10.4$ & $17.6 \pm 9.9$ & & $16.4 \pm 9.6$ & $15.1 \pm 8.4$ \\
$\quad$ Animal fat (g) & $2.4 \pm 3.4$ & $2.6 \pm 4.5$ & & $1.6 \pm 2.9$ & $1.7 \pm 3.6$ \\
Animal fat ratio (\%) & $13.7 \pm 19.6$ & $13.5 \pm 21.4$ & & $10.7 \pm 19.1$ & $9.9 \pm 18.8$ \\
Crude fiber (g) & $13.4 \pm 7.7$ & $7.5 \pm 4.2^{* * *}$ & & $12.0 \pm 7.4$ & $7.7 \pm 3.9^{* * *}$ \\
Sodium (g) & $4.3 \pm 2.4$ & $4.7 \pm 2.6$ & & $4.2 \pm 2.5$ & $4.3 \pm 2.6$ \\
Potassium (g) & $2.0 \pm 0.9$ & $1.6 \pm 0.7^{* * *}$ & & $1.8 \pm 0.9$ & $1.6 \pm 0.7^{* *}$ \\
Calcium (mg) & $331 \pm 170$ & $324 \pm 161$ & & $307 \pm 291$ & $291 \pm 145$ \\
Magnesium (mg) & $551 \pm 498$ & $378 \pm 314^{* * *}$ & & $454 \pm 409$ & $319 \pm 275^{* * *}$ \\
Cereal energy (kcal) & $1,963 \pm 816$ & $1,523 \pm 708^{* * *}$ & & $1,752 \pm 786$ & $1,453 \pm 669^{* * *}$ \\
Cholesterol (mg) & $9.5 \pm 30.3$ & $18.7 \pm 45.1$ & & $7.7 \pm 28.5$ & $11.4 \pm 36.5$ \\
Saturated F.A. ${ }^{a}$ (g) & $4.4 \pm 2.3$ & $5.4 \pm 3.0^{* * *}$ & & $3.7 \pm 2.2$ & $4.7 \pm 2.6^{* * *}$ \\
Monounsaturated F.A. ${ }^{a}(\mathrm{~g})$ & $7.3 \pm 3.9$ & $5.5 \pm 3.1^{* * *}$ & & $6.2 \pm 3.7$ & $4.8 \pm 2.7^{* * *}$ \\
Polyunsaturated F.A. ${ }^{a}(\mathrm{~g})$ & $7.5 \pm 4.0$ & $6.6 \pm 3.7^{* * *}$ & & $6.5 \pm 3.8$ & $5.7 \pm 3.2^{* * *}$ \\
\hline
\end{tabular}

$\mathrm{M} \pm \mathrm{SD} .{ }^{\mathrm{a}}$ Fatty acid. ${ }^{*} p<0.05,{ }^{* *} p<0.01,{ }^{* * *} p<0.001$ (vs. Kotyang). 
Table 6. Simple correlation coefficients between total serum cholesterol and nutrient intakes.

\begin{tabular}{llr}
\hline & \multicolumn{1}{c}{ Men } & Women \\
\hline Energy & $-0.247^{* * *}$ & 0.002 \\
Protein & $-0.250^{* * *}$ & -0.002 \\
Fiber & $-0.231^{* * *}$ & -0.017 \\
Potassium & $-0.230^{* * *}$ & 0.005 \\
Magnesium & $-0.124^{* *}$ & -0.020 \\
Cereal energy & $-0.124^{* *}$ & -0.005 \\
PUFA $^{\mathrm{a}}$ & $-0.152^{* *}$ & 0.029 \\
Alcohol & -0.0407 & -0.057 \\
\hline
\end{tabular}

${ }^{a}$ Polyunsaturated fatty acid. ${ }^{* *} p<0.01,{ }^{* * *} p<0.001$.

vitamin $\mathrm{A}$ of the villagers in Kotyang were higher than those in Bhadrakali. $\mathrm{Na}$ and $\mathrm{Ca}$ intakes in the two villages were almost the same. $\mathrm{Mg}$ intake was significantly higher in both sexes in Kotyang than in Bhadrakali.

Fatty acid composition is shown in Table 5. Polyunsaturated fatty acid (P) and monounsaturated fatty acid intakes were higher in Kotyang than in Bhadrakali in both sexes, while saturated fatty acids (S) were lower in both sexes in Kotyang than in Bhadrakali. The $\mathrm{P} / \mathrm{S}$ ratio was higher in Kotyang than in Bhadrakali.

Energy derived from animal products was 3-4\% of total energy. Animalprotein and animal-fat ratios were similar in both villages. Carbohydrate was mainly ingested from corn, rice, and gaffun. Corn was ingested more in Kotyang than in Bhadrakali. Sugar and soft drinks were not taken at all in Kotyang, but were considerably consumed in Bhadrakali. Therefore, the subjects in Kotyang ingested more complex and less single carbohydrates than those in Bhadrakali.

\section{Individual-based correlation analyses}

A significant simple positive correlation between total cholesterol and age $(r=$ $0.242, p<0.001$ for men; $r=0.114, p<0.05$ for women) or $\%$ Fat $(r=0.108, p<$ $0.05 ; r=0.170, p<0.01)$ was observed. Again, a significant simple negative correlation for men between total cholesterol and $\dot{V}_{\mathrm{O}_{2} \max }(r=-0.355, p<0.001)$ was observed. However, the correlation coefficient after adjustment for the effect of age and $\%$ Fat lowered $(r=-0.143$, not significant $)$ as compared with the simple correlation coefficient, indicating that the correlation between $\dot{V}_{\mathrm{O}_{2} \max }$ and total serum cholesterol was dependent in part on both $\%$ Fat and age.

The simple correlations between total serum cholesterol and dietary intake are shown in Table 6. Total serum cholesterol showed significant negative associations with energy intake, protein, fiber, cereal energy, $\mathrm{K}, \mathrm{Mg}$, and polyunsaturated fatty acid only in men, but did not in women. Alcohol intake was not correlated with total serum cholesterol, but was significantly associated with HDL-cholesterol ( $r=$ $0.233, p<0.001)$ and triglyceride $(r=-0.183, p<0.01)$ in men, respectively. However, intake of energy, protein, $\mathrm{K}$, and $\mathrm{Mg}$ was negatively correlated with age 
Table 7. Partial correlation coefficients between total serum cholesterol and nutrient intakes adjusted by age.

\begin{tabular}{llc}
\hline & \multicolumn{1}{c}{ Men } & Women \\
\hline Energy & $-0.217^{* * *}$ & 0.016 \\
Protein & $-0.217^{* * *}$ & -0.007 \\
Fiber & $-0.212^{* *}$ & 0.005 \\
Potassium & $-0.108^{*}$ & 0.018 \\
Magnesium & $-0.125^{* *}$ & -0.054 \\
Cereal energy & $-0.207^{* * *}$ & $-0.188^{* *}$ \\
PUFA $^{\mathrm{a}}$ & $-0.109^{*}$ & 0.043 \\
Alcohol & -0.036 & -0.061 \\
\hline
\end{tabular}

${ }^{a}$ Polyunsaturated fatty acid. ${ }^{*} p<0.05,{ }^{* *} p<0.01,{ }^{* * *} p<0.001$.

(data not shown).

As shown in Table 7, statistically significant negative correlations were found between serum total cholesterol and the intake of energy, protein, fiber, $\mathrm{K}, \mathrm{Mg}$, and polyunsaturated fatty acid after the adjustment for the effect of age in men and between total serum cholesterol and the intake of cereal energy in men and women, respectively. Alcohol intake was not associated with total serum cholesterol in both sexes, while the correlation between HDL-cholesterol and alcohol intake was found to be statistically significant in men $(r=0.227, p<0.001)$.

\section{DISCUSSION}

Total serum cholesterol is generally considered to be determined partially by the intake of dietary cholesterol, $\mathrm{P} / \mathrm{S}$ ratio, total fat intake, and total calories $(1-6)$, while other cross-sectional surveys have shown poor correlation between dietary cholesterol and total serum cholesterol in serum (10). In this study, both total and animal fat intakes were not different between Kotyang and Bhadrakali. No correlation was observed between the fat intake and the total serum cholesterol in spite of the fact that the significant difference in total serum cholesterol level was observed in the two villages.

Dietary $\mathrm{K}$ and $\mathrm{Mg}$ intakes were greater in Kotyang than in Bhadrakali in both sexes. We have reported that high $\mathrm{K}$ intake statistically significantly decreases both total serum cholesterol and triglyceride concentration not only in healthy young women (11) but also in elderly subjects associated with increased frequency of hyperlipidemia (12), probably through the activation of lipoprotein lipase (LPL) activity resulting from the increase in plasma insulin (13). On the other hand, $\mathrm{Mg}$ deficiency increased the total serum cholesterol and triglyceride level, probably due to the deficiency of lecithin-cholesterol acyl transferase (LCAT) activity (14-16). Several epidemiological studies have indicated the relationship between dietary $\mathrm{Mg}$ intake and ischemic heart diseases (17-21). Furthermore, animal experiments have shown that $\mathrm{Mg}$ deficiency causes atherogenic alterations in blood lipid composition. 
These observations, combined with the knowledge that high blood lipid composition is one of the major risk factors for development of cardiovascular disease, have led to the suggestion that the marginal $\mathrm{Mg}$ deficiency may contribute to a higher level of the serum lipids and to a higher risk of ischemic heart disease (22). From these observations, our results suggest that the high $\mathrm{Mg}$ and $\mathrm{K}$ intakes may contribute to the lower total serum cholesterol and triglyceride levels in Kotyang. On the other hand, high $\mathrm{Mg}$ intake has been associated with increased LCAT activity, so the high $\mathrm{Mg}$ intake in Kotyang was considered to be one of the contributing factors in the absence of any significant difference in HDL-cholesterol between the two groups of villagers.

Fiber intake was significantly greater in Kotyang than in Bhadrakali, and was exceedingly greater in both villages than in Japan (23). We have reported that a high fiber intake decreases total serum cholesterol and triglycerides to a certain extent in healthy young women (24). Several clinical studies have already indicated the relationship between fiber intake and lipid metabolism (25-30). Corn was consumed more in Kotyang than in Bhadrakali and the relationship of wheat consumption was reversed. Since corn fiber is said to be more effective in lowering serum lipids than wheat fiber (31), a higher fiber intake was considered to be one of the contributing factors in lower total serum cholesterol levels in Kotyang.

The composition of carbohydrate in Kotyang was different from that of Bhadrakali; the intake of complex carbohydrates was greater in Kotyang than in Bhadrakali, and the intake of simple carbohydrates such as sugar was the reverse. Mancini and Parillo have emphasized in the dietary guidelines of European Atherosclerosis Society policy statement for the prevention of coronary heart disease (32) that the amount of lipid and saturated fatty acids should be reduced and replaced by complex carbohydrates and fiber.

In the present study, the polyunsaturated fatty acid intake and the $\mathrm{P} / \mathrm{S}$ ratio were higher in Kotyang than in Bhadrakali. These results are consistent with the previous reports that high intake of polyunsaturated fatty acid and high $\mathrm{P} / \mathrm{S}$ ratio decrease total serum cholesterol level (33-35).

High alcohol consumption is emerging as an important risk factor for hypertriglyceridemia in many populations, but was not for hypercholesterolemia $(36,37)$. In the present study, alcohol intake was not significantly associated with total serum cholesterol, either. The villagers in Kotyang usually drink "Chan," which contains 2-3\% pure alcohol, throughout the day. As the average alcohol intake for Kotyang's men is thought to be modest and favorable, it might be one of the beneficial effects producing a lower prevalence of hyperlipemia in them. On the other hand, alcohol intake was significantly associated with HDL-cholesterol only in men, as reported by Eisenberg (38). Incidentally, high intake of red peppers in both villages may also have some effects for lowering serum lipids since capsaicin in red peppers has been reported to affect serum total cholesterol level $(39,40)$.

The partial correlation adjusted for age between total serum cholesterol level and $\%$ Fat was significantly positive, whereas those between total serum cholesterol 
and $\mathrm{K}, \mathrm{Mg}$, fiber intake, and cereal energy ratio were significantly negative, respectively. The association between dietary cations and total serum cholesterol level established in this study was independent not only of age and $\%$ Fat but also of cereal energy ratio and fiber intake.

On the other hand, there was no statistically significant association between serum albumin and total serum cholesterol level when analyzed by the chi-square test. Moreover, most of the Nepalese people who participated in this study were very active and clinically healthy, indicating that the lower total cholesterol level is not due to poor health.

The level of habitual activity is considered to be the most important factor influencing $\dot{V}_{\mathrm{O}_{2} \max }$. The correlation between total serum cholesterol and $\dot{V}_{\mathrm{O}_{2} \max }$ adjusted for age and $\%$ Fat was negative and statistically significant for men, suggesting that the higher physical activity may work to lower total serum cholesterol level in Kotyang and to keep HDL-cholesterol levels equal in both villages as reported previously $(41,42)$. Serum triglyceride levels were significantly lower in Kotyang than in Bhadrakali in both sexes. High physical activity and high $\mathrm{K}$ and $\mathrm{Mg}$ intakes observed in Kotyang's villagers may have influence on triglyceride rich lipoprotein catabolism via increased lipoprotein lipase activities, and the lower body mass index in Kotyang may also cause the lower serum triglyceride level to a certain extent $(43,44)$.

Both single and partial correlations between total serum cholesterol level and most variables in the dietary composition calculated were not significant in women, probably because the difference in total serum cholesterol levels between women in both villages was not as different as the difference between men.

In conclusion, the dietary survey in the present study strongly suggests that in addition to the higher physical activity and the lower $\%$ Fat, the higher intakes of complex carbohydrate, fiber, $\mathrm{K}$, and $\mathrm{Mg}$ rather than the lower total fat intake may contribute to maintain the total serum cholesterol and triglyceride concentrations at lower levels in Kotyang than in Bhadrakali.

We wish to thank Professors S. Kobayashi and S. Konomi, Mr. K. Nakajima, Ms. M. Yamane, Drs. S. Dhungel, S. Sharma, and P. Upadya, Mr. and Mrs. K. B. Tamang for their excellent cooperation, and Mr. B. Jha and Mr. D. Sada for their technical assistance. This work was supported in part by Grant-in-Aid for Overseas Scientific Surveys from Ministry of Education, Science and Culture, Japan (No. 62041068 and No. 63043055) and by Research Grant from Kyushu University (1987).

\section{REFERENCES}

1) Grundy, S. M., and Ahrens, E. H., Jr. (1970): The effects of unsaturated dietary fats on absorption, excretion, synthesis, and distribution of cholesterol in man. J. Lipid Res., 49, 1135-1152.

2) Connor, W. E., Hodges, R. E., and Bleir, R. E. (1961): The serum lipids in men 
receiving high cholesterol and cholesterol-free diets. J. Clin. Invest., 40, 894-901.

3) Mattson, F. H., Erickson, B. A., and Kligman, A. H. (1972): Effect of dietary cholesterol on serum cholesterol in man. Am. J. Clin. Nutr., 25, 589-594.

4) Schonfeld, G., Patch, W., Rudel, L. L., Nelson, C., Epstein, W., and Olson, R. E. (1982): Effects of dietary cholesterol and fatty acids on plasma lipoproteins. J. Clin. Invest., 69, 1072-1080.

5) Ahrens, E. H., Jr. (1982): Dietary fat and coronary heart disease: Unfinished business. Lancet, ii, 1121-1124.

6) Keys, A. (1984): Serum cholesterol response to dietary cholesterol. Am. J. Clin. Nutr., 40, 351-359.

7) Kawasaki, T., Itoh, K., Uezono, K., Ogaki, T., Yoshimizu, Y., Kobayashi, S., Osaka, T., Ogata, M., Dhungel, S., Sharma, S., and Acharya, G. A. (1993): Investigation of high salt intake in a Nepalese population with low blood pressure. J. Hum. Hypertens., 7, 131-140.

8) Nagamine, S., and Suzuki, S. (1964): Anthrometry and body composition of Japanese young men and women. Hum. Biol., 36, 8-15.

9) Margaria, R., Aghemo, P., and Rovelli, E. (1965): Indirect determination of $\mathrm{O}_{2}$ consumption in man. J. Appl. Physiol., 20, 1070-1073.

10) Mann, G. V., Pearson, G., Gordon, T., and Dawber, T. R. (1962): Diet and cardiovascular disease in the Framingham Study. I. Measurement of dietary intake. Am. J. Clin. Nutr., 11, 200-225.

11) Itoh, K., Kawasaki, T., and Uezono, K. (1990): Effects of high potassium intake on blood pressure and lipid and carbohydrate metabolism in healthy young women. $J$. Jpn. Soc. Nutr. Food. Sci., 43, 241-245 (in Japanese with English abstract).

12) Kawasaki, T., Itoh, K., Uezono, K., and Sasaki, H. (1989): Effect of potassium intake on blood pressure and lipid metabolism in normotensive and hypertensive subjects. Abstract of the 14th International Congress of Nutrition, August 20-25, Seoul, Korea, p. 373.

13) Parkin, S. M., Walker, K., Ashby, P., and Robinson, D. S. (1980): Effects of glucose and insulin on the activation of lipoprotein lipase and on protein synthesis in rat adipose tissue. Biochem. J., 188, 193-199.

14) Rayssiguier, Y. (1984): Role of magnesium and potassium in the pathogenesis of arteriosclerosis. Magnesium, 3, 226-238.

15) Rayssiguier, Y., Gueux, E., and Weiser, D. (1981): Effects of magnesium deficiency lipid metabolism in rats fed a high carbohydrate diet. J. Nutr., 111, 1876-1883.

16) Gueux, E., Rayssiguier, Y., Piot, M. C., and Alciner, L. (1984): Reduction of plasma lecithin-cholesterol acyltransferase activity by acute magnesium deficiency in the rat. J. Nutr., 114, 1479-1483.

17) Schroeder, H. A., and Brattleboro, W. (1960): Relations between hardness of water and death rates from certain chronic and degenerative diseases in the United States. $J$. Chronic. Dis., 12, 586-591.

18) Schroeder, H. A. (1966): Municipal drinking water and cardiovascular death rates. JAMA, 95, 125-129.

19) Marier, J. R. (1978): Cardio-projective contribution of hard waters to magnesium intake. Rev. Can. Biol., 37, 115-125.

20) Sharrett, A. R. (1979): The role of chemical constituents of drinking water in 
cardiovascular disease. Am. J. Epidemiol., 110, 401-419.

21) Luoma, H., Aromaa, A., and Helminen, S. (1983): Risk of myocardial infarction in Finnish men in relation to fluoride, magnesium and calcium concentration in drinking water. Acta Med. Scand., 213, 171-176.

22) Sandvad, R. H., Aurup, P., Goldstein, K., McNair, P., Mortensen, P. B., Larsen, O. G., and Lawaetz, H. (1989): Inffuence of magnesium substitution therapy on blood lipid composition in patients with ischemic heart disease. Arch. Intern. Med., 149, 1050-1053.

23) Minowa, M., Bingham, S., and Cummings, H. (1983): Dietary fiber intake in Japan. Hum. Nutr. Appl. Nutr., 37A, 113-119.

24) Itoh, K., Kawasaki, T., and Uezono, K. (1990): Effects of high fiber diet on blood pressure and lipid and carbohydrate metabolism in healthy young women. J. Jpn. Soc. Nutr. Food. Sci., 43, 233-239 (in Japanese with English abstract).

25) Williams, P. T., Krauss, R. M., Kindel-Joyce, S., Dreon, D. M., Vranizan, K. M., and Wood, P. D. (1986): Relationship of dietary fat, protein, cholesterol and fiber intake to atherogenic lipoproteins in men. Am. J. Clin. Nutr., 44, 787-797.

26) Kritchevsky, D. (1987): Dietary fibre and lipid metabolism. Int. J. Obes., 11 (Suppl. 1), 33-43.

27) Edington, J., Geekie, M., Carter, R., Benfield, L., Fisher, K., Ball, M., and Mann, J. (1987): Effect of dietary cholesterol on plasma cholesterol concentration in subjects following reduced fat, high nibre diet. Br. Med. J., 294, 333-336.

28) Anderson, J. W., Linchen, W. J., and Sieling, B. (1980): Hypolipidemic effects of high carbohydrate, high-fiber diets. Metabolism, 29, 551-558.

29) Anderson, J. W., and Bryant, C. A. (1986): Dietary fiber: Diabetes and obesity. Am. J. Gastroenterol., 81, 898-906.

30) Hallfrisch, J., Tobin, J. D., Muller, D. C., and Andrese, R. (1988): Fiber intake, age and other coronary rick factors in men of the Baltimor Longitudinal Study (19591975). J. Gerontol.; Med. Sci., 43, M64-M68.

31) Takeuchi, M., Sugawara, M., Takasho, T., Egashira, Y., Sanada, H., and Ayano, Y. (1990): Development of corn dietary fiber materials with physiological functions. $J$. Jpn. Soc. Food. Sci. Technol., 38, 981-989 (in Japanese with English abstract).

32) Mancini, M., and Parillo, M. (1991): Lipid intake and atherosclerosis. Ann. Nutr. Metab., 35 (Suppl. 1), 103-108.

33) Keys, A., Anderson, J. T., and Grande, F, (1965): Serum cholesterol response to changes in the diets. Metabolism, 14, 747-787.

34) Keys, A., Anderson, J. T., and Grande, F. (1957): Serum cholesterol response to dietary fat. Lancet, 272, 787.

35) Hegsted, D. M., McGandy, R. B., and Myers, M. L., and Stare, F. J. (1965): Quantitative effects of dietary fat on serum cholesterol in man. Am. J. Clin. Nutr., 17, 281-295.

36) Lowsky, M. S., Jones, D. P., Davidson, C. S., and Lieber, C. S. (1963): Studies of alcoholic hyperlipidemia and its mechanism. Am. J. Med., 35, 794-802.

37) Bead, J. D., and Barborick, J. J. (1965): Plasma lipids of days during and after chronic ethanol administration. Proc. Soc. Exp. Biol. Med., 118, 1151-1154.

38) Eisenberg, S. (1984): High density lipoprotein metabolism. J. Lipid Res., 25, 10171058. 
39) Henry, C. J. K., and Emery, B. (1986): Effect of spiced food metabolic rate. Hum. Clin. Nutr., 40C, 165-168.

40) Watanabe, T., Kawada, T., and Iwai, K. (1987): Enhancement by capsaicin of energy metabolism in rats through secretion of catecholamine from adrenal medulla. Agric. Biol. Chem., 51, 75-79.

41) Stubbe, I., Hansson, P., Gustafson, A., and Nilsson-Ehle, P. (1983): Plasma lipoproteins and lipolytic enzyme activities during endurance training in sedentary men: Changes in high density lipoprotein subfractions and composition. Metabolism, 32, 1120-1127.

42) Peltonon, P., Marniemi, J., Hietanan, E., Vuori, I., and Ehnholm, C. (1983): Change in serum lipids, lipoprotein, and heparin releasable lipolytic enzymes during moderate physical training in man: A longitudinal study. Metabolism, 3, 518-526.

43) Tokunaga, K., Ishikawa, K., and Matsuzawa, Y. (1982): Lipids and lipoproteins during a very-low caloric diet. Int. J. Obes., 6, 416.

44) Wolf, R. N., and Grundy, S. M. (1983): Influence of weight reduction on plasma lipoprotein in obese patients. Arteriosclerosis, 3, 160-169. 